Supplement of Geosci. Model Dev., 13, 4749-4771, 2020

https://doi.org/10.5194/gmd-13-4749-2020-supplement

(C) Author(s) 2020. This work is distributed under

the Creative Commons Attribution 4.0 License.

(c) (1)

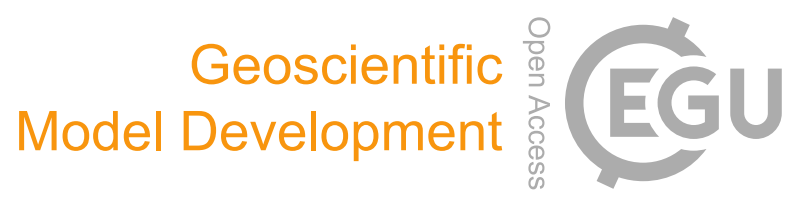

Supplement of

\title{
Role of atmospheric horizontal resolution in simulating tropical and subtropical South American precipitation in HadGEM3-GC31
}

Paul-Arthur Monerie et al.

Correspondence to: Paul-Arthur Monerie (pmonerie@gmail.com)

The copyright of individual parts of the supplement might differ from the CC BY 4.0 License. 

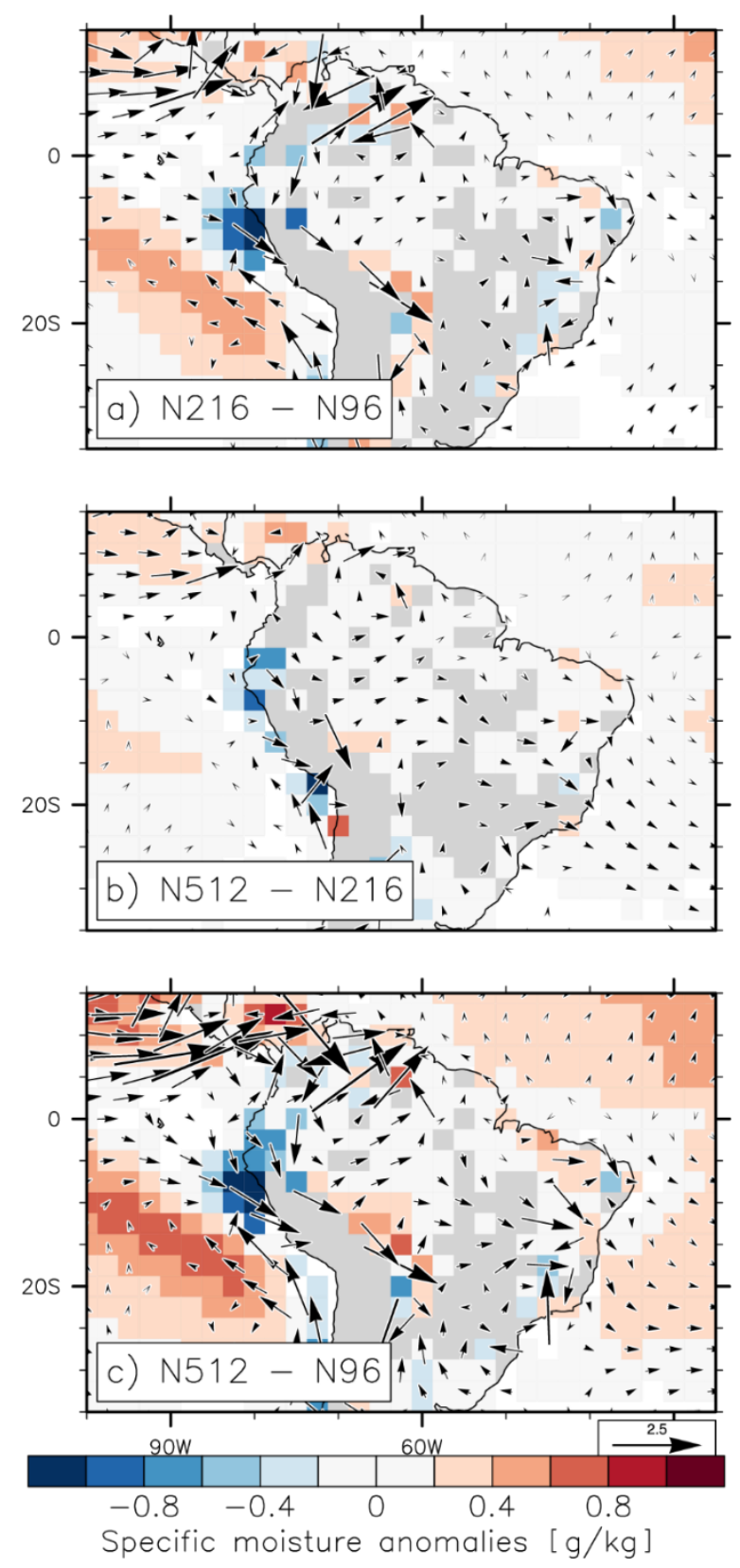

Figure S1: Ensemble-mean difference in annual mean surface specific humidity (g.kg ${ }^{-1}$ ) and $850 \mathrm{hPa}$ wind (m.s. ${ }^{-1}$ ), for (a) N216-N96, (b) N512-N216 and (c) N512-N96. 

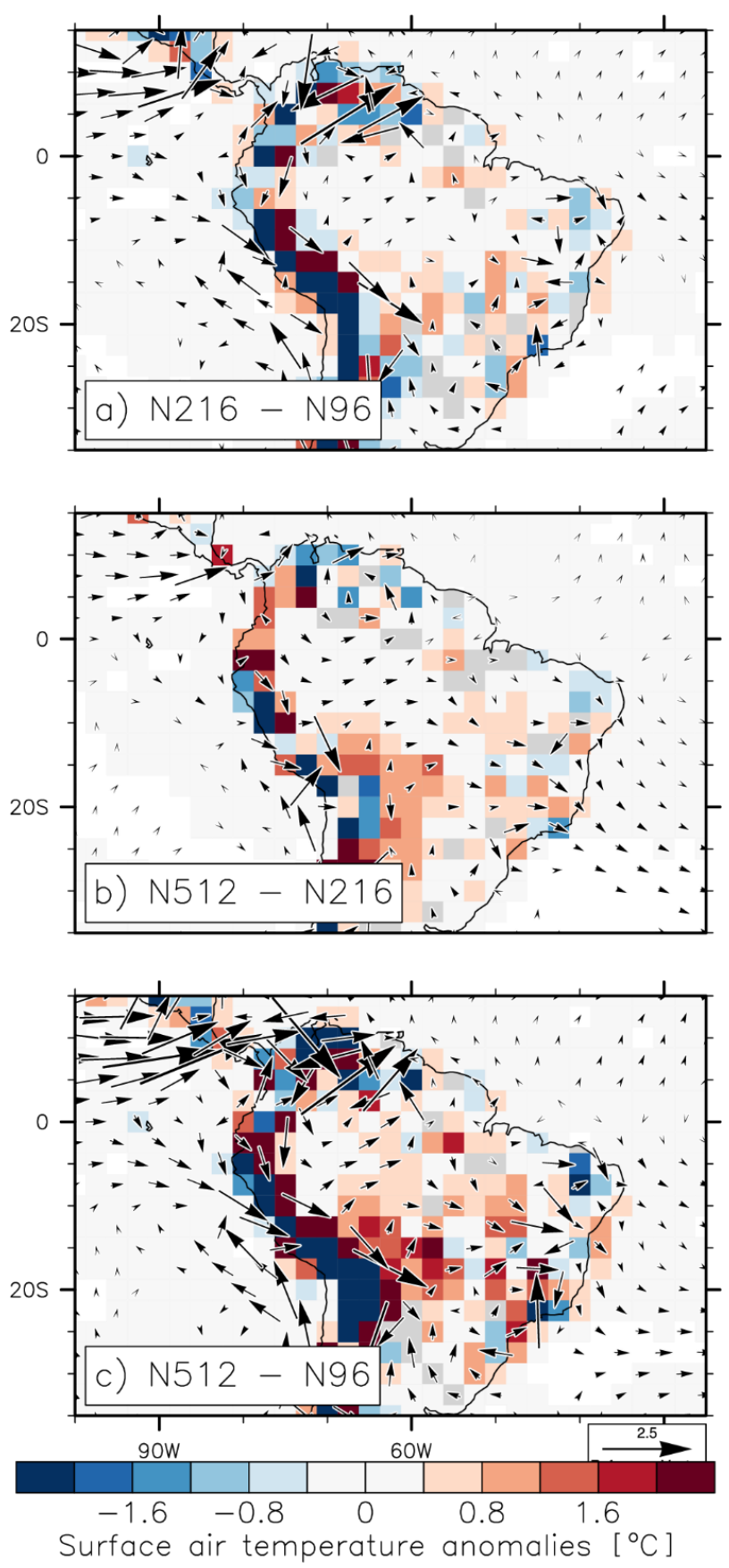

Figure S2: Ensemble-mean difference in annual mean surface air temperature $\left({ }^{\circ} \mathrm{C}\right)$ and $850 \mathrm{hPa}$ wind $\left(\mathrm{m} . \mathrm{s}^{-1}\right)$, for (a) N216-N96, (b) N512-N216 and (c) N512-N96. 
a) Observations (GPCC/NCEP)
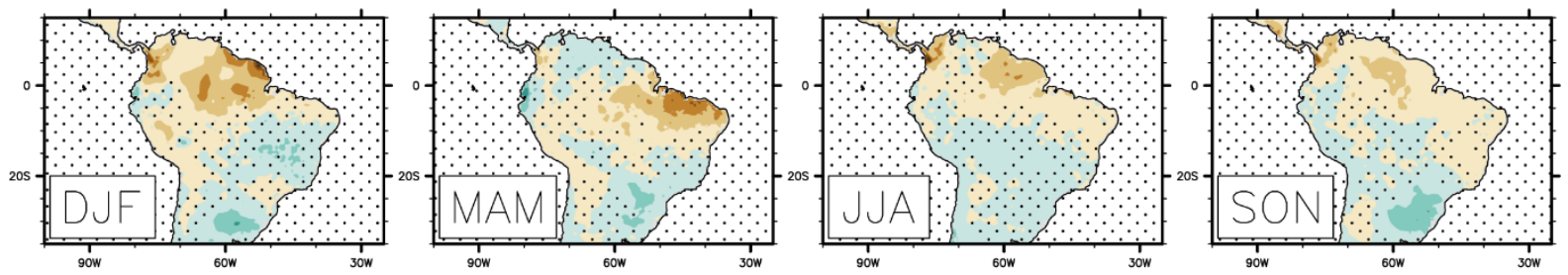

b) N96

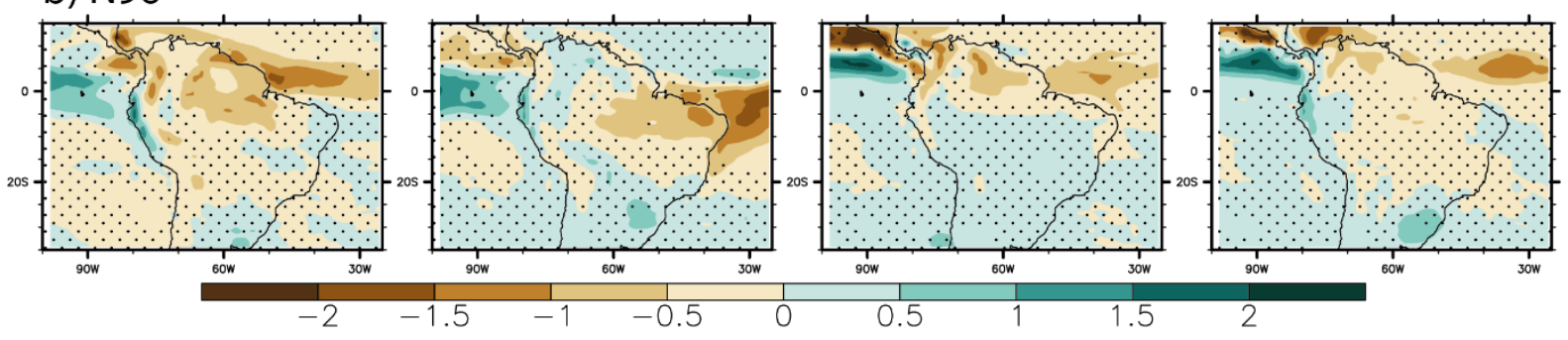

c) N96 - observations
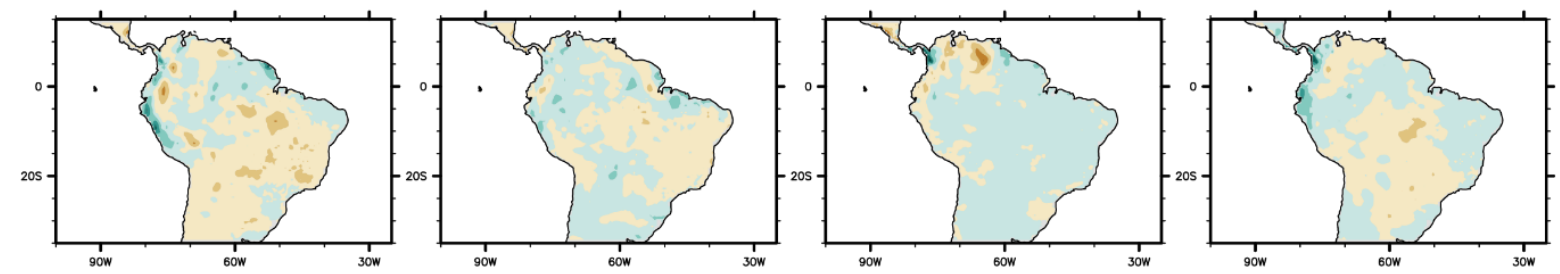

d) N512 - observations

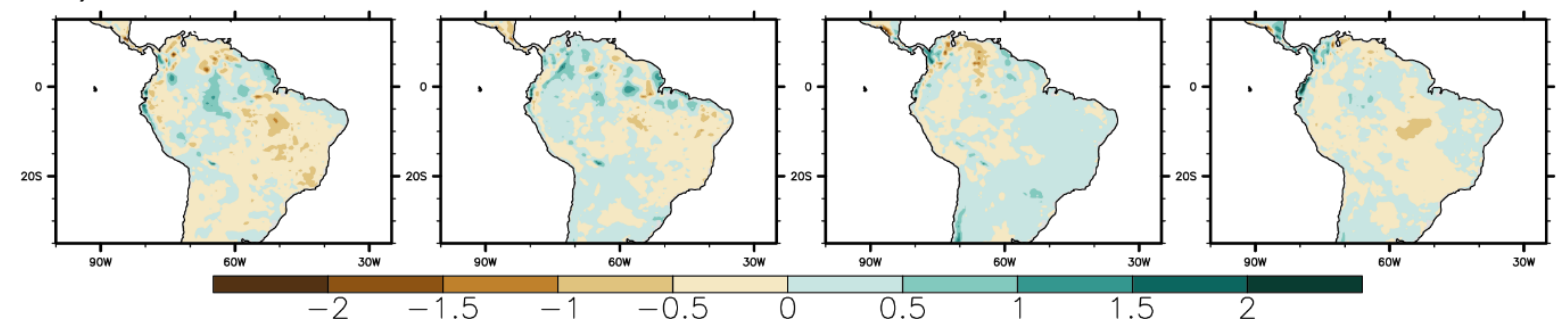

Figure S3: Precipitation regressed onto the EN3.4 index (mm.day $\left.{ }^{-1} \cdot \mathrm{C}^{-1}\right)$ with (a) observations (GPCC for precipitation and NCEP for temperature), (b) N96. Stippling is added when regression is not significant, using a Student's t-test and a 95\% confidence level. Difference between (c) N96 and observations (i.e. (b)-(a)) and (d) N512 and observations. 

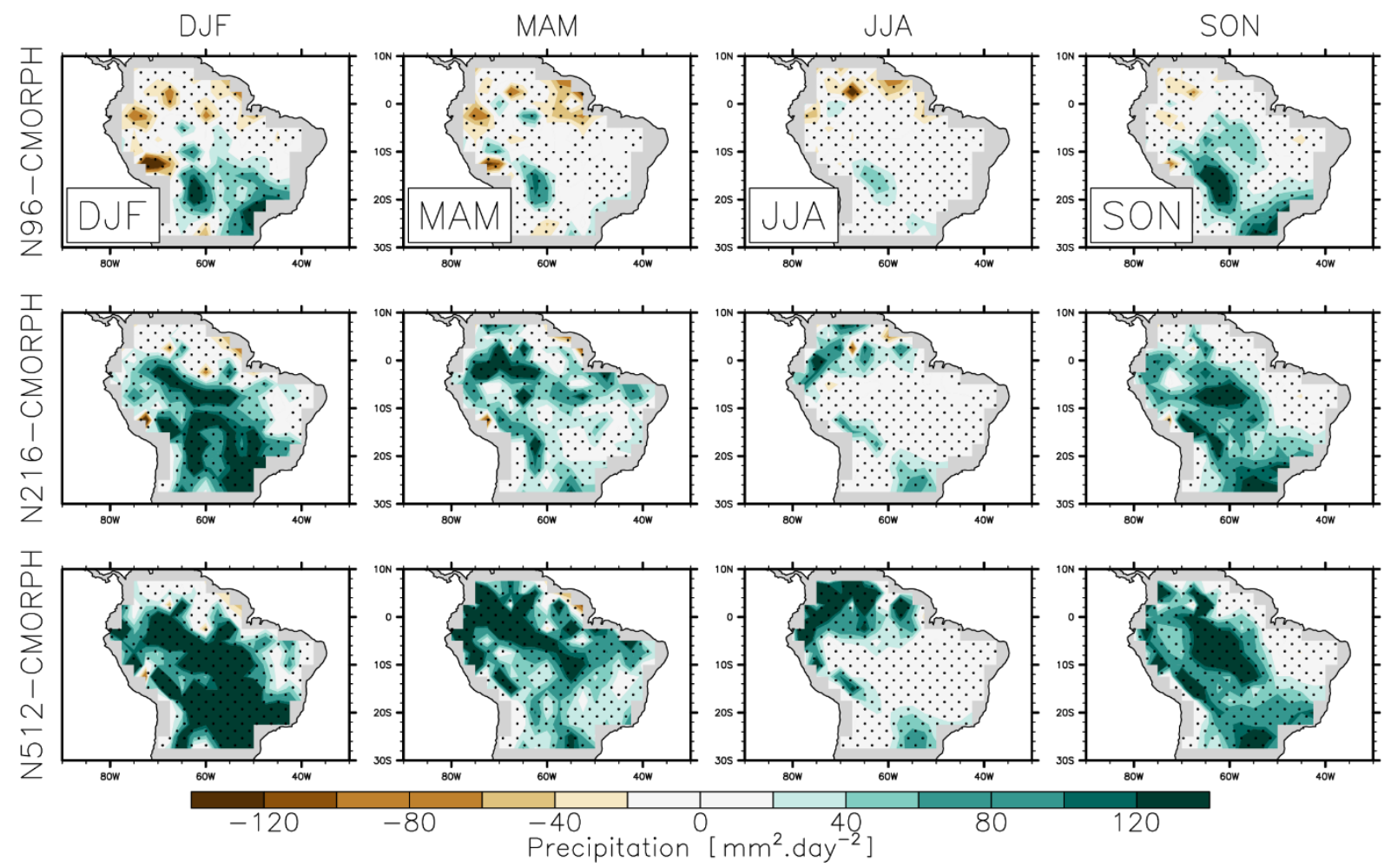

Figure S4: Bias in daily precipitation variance $\left(\mathrm{mm}^{2}\right.$.day-2) in (top row) N96, (middle row) N216 and (bottom row) N512, with regard to CMORPH. Results are given for the DJF, MAM, JJA and SON seasons, over the 1998-2014 period. Stippling indicates that differences are significant according to an f-test and a $95 \%$ confidence level. 

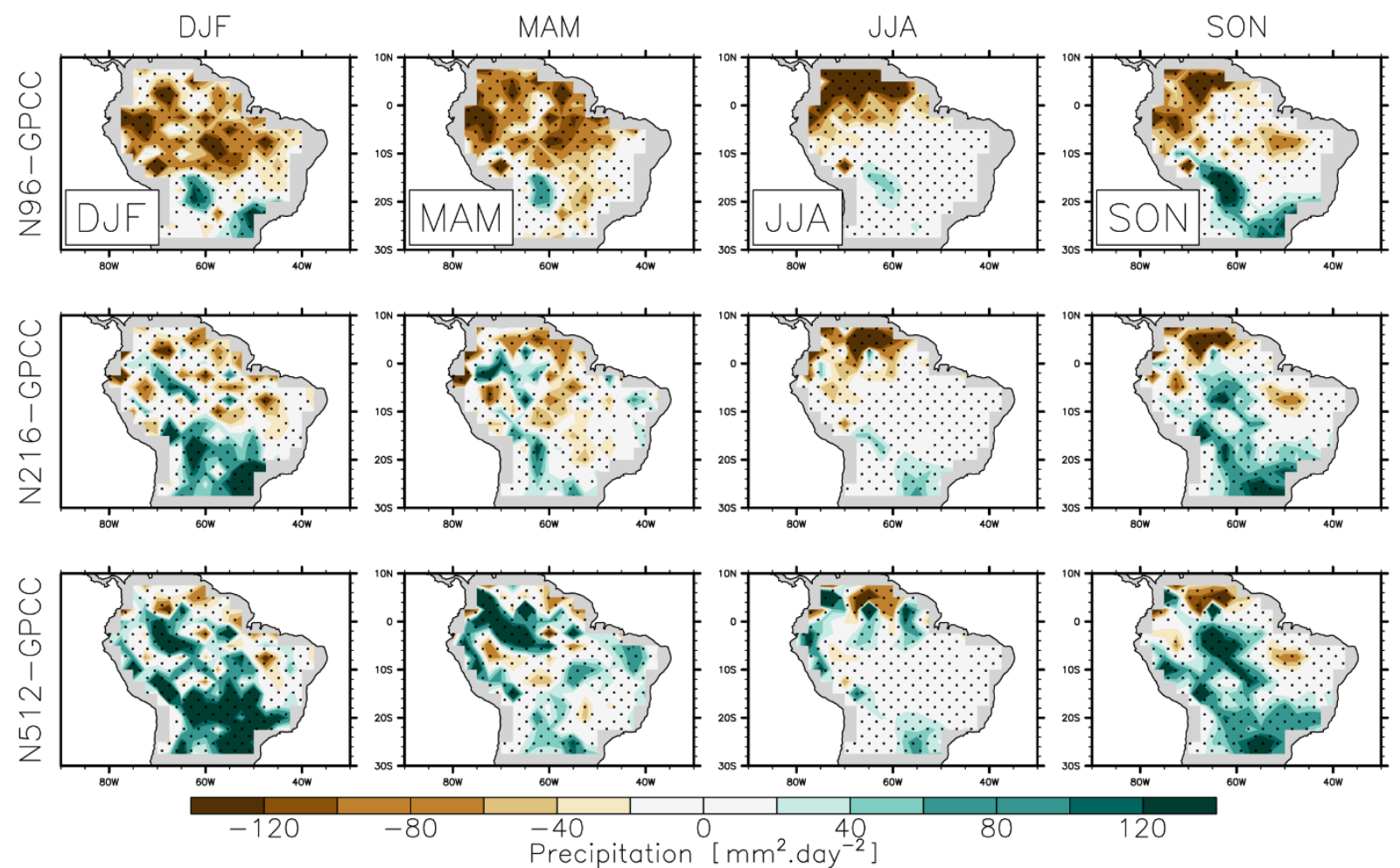

Figure S5: Bias in daily precipitation variance $\left(\mathrm{mm}^{2}\right.$.day-2) in (top row) N96, (middle row) N216 and (bottom row) N512, with regard to GPCC. Results are given for the DJF, MAM, JJA and SON seasons, over the 1998-2014 period. Stippling indicates that differences are significant according to an f-test and a $95 \%$ confidence level. 

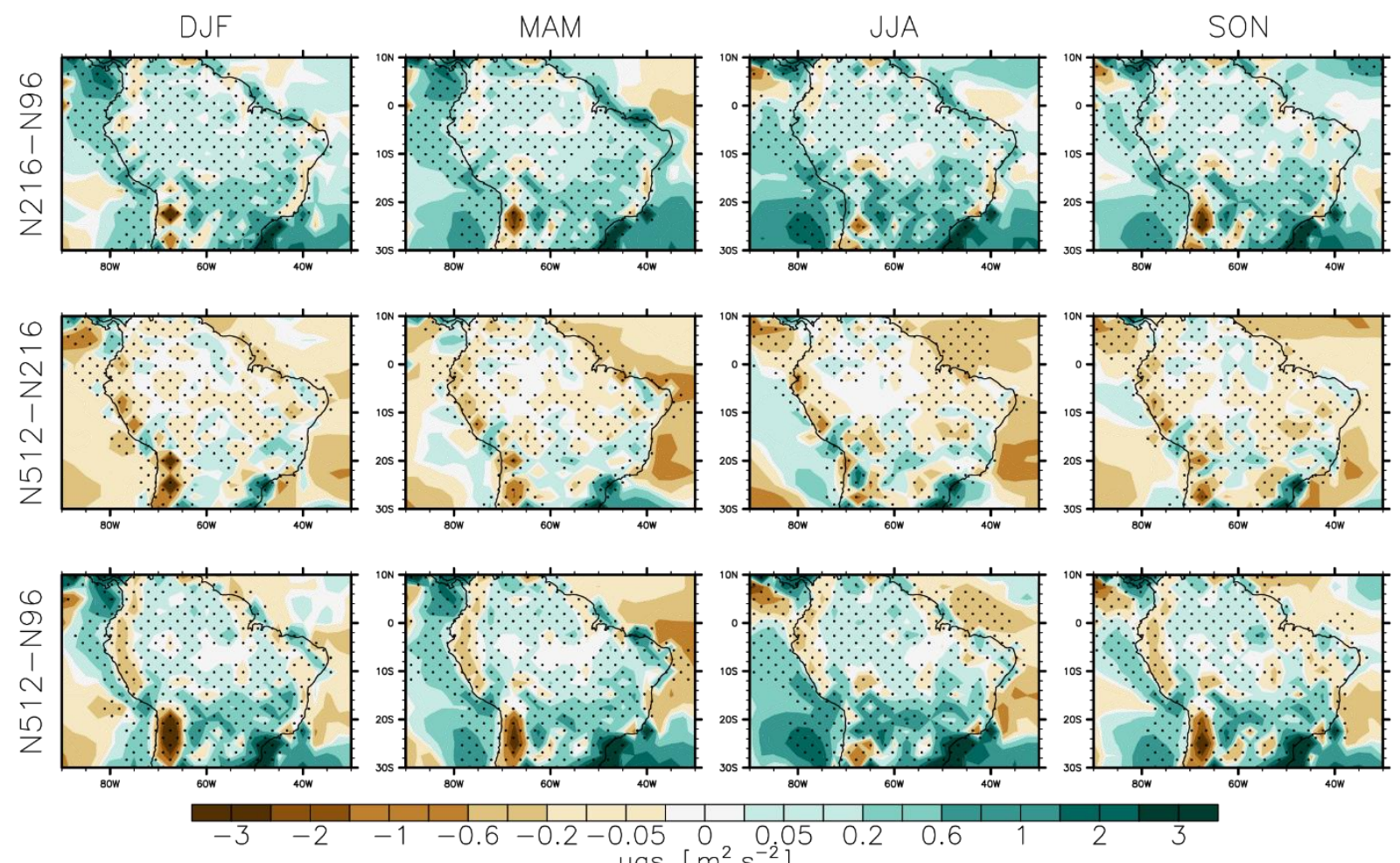

Figure S6: Ensemble-mean difference in surface zonal wind daily variance $\left(\mathrm{m}^{2} . \mathrm{s}^{-2}\right)$, for (top row) N216N96, (middle row) N512-N216 and (bottom row) N512-N96. Results are given for the DJF, MAM, JJA and SON seasons, over the 1998-2014 period. Stippling indicates that differences are significant according to an f-test and a 95\% confidence level. 

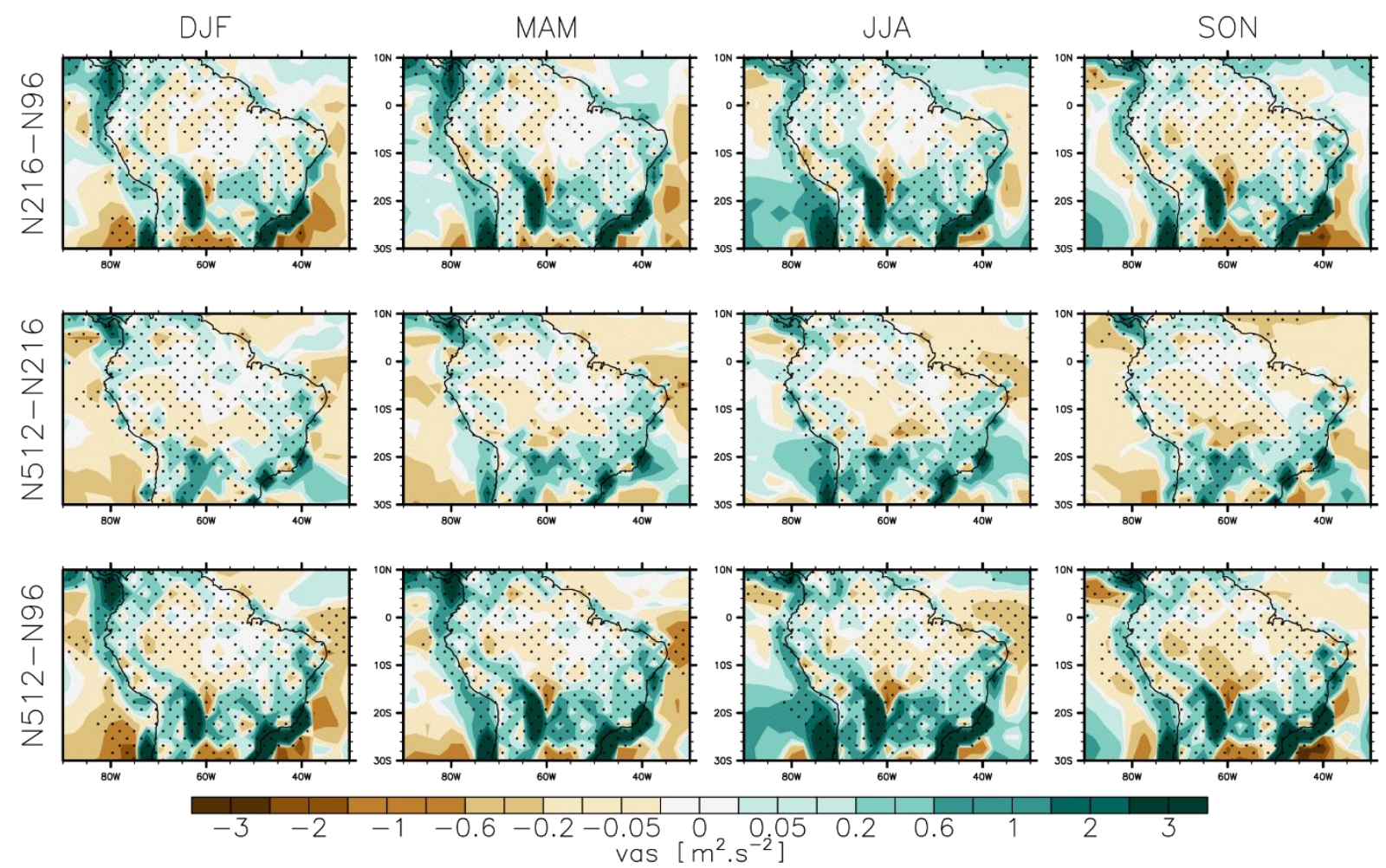

Figure S7: As in Figure S6 but for surface meridional wind. 

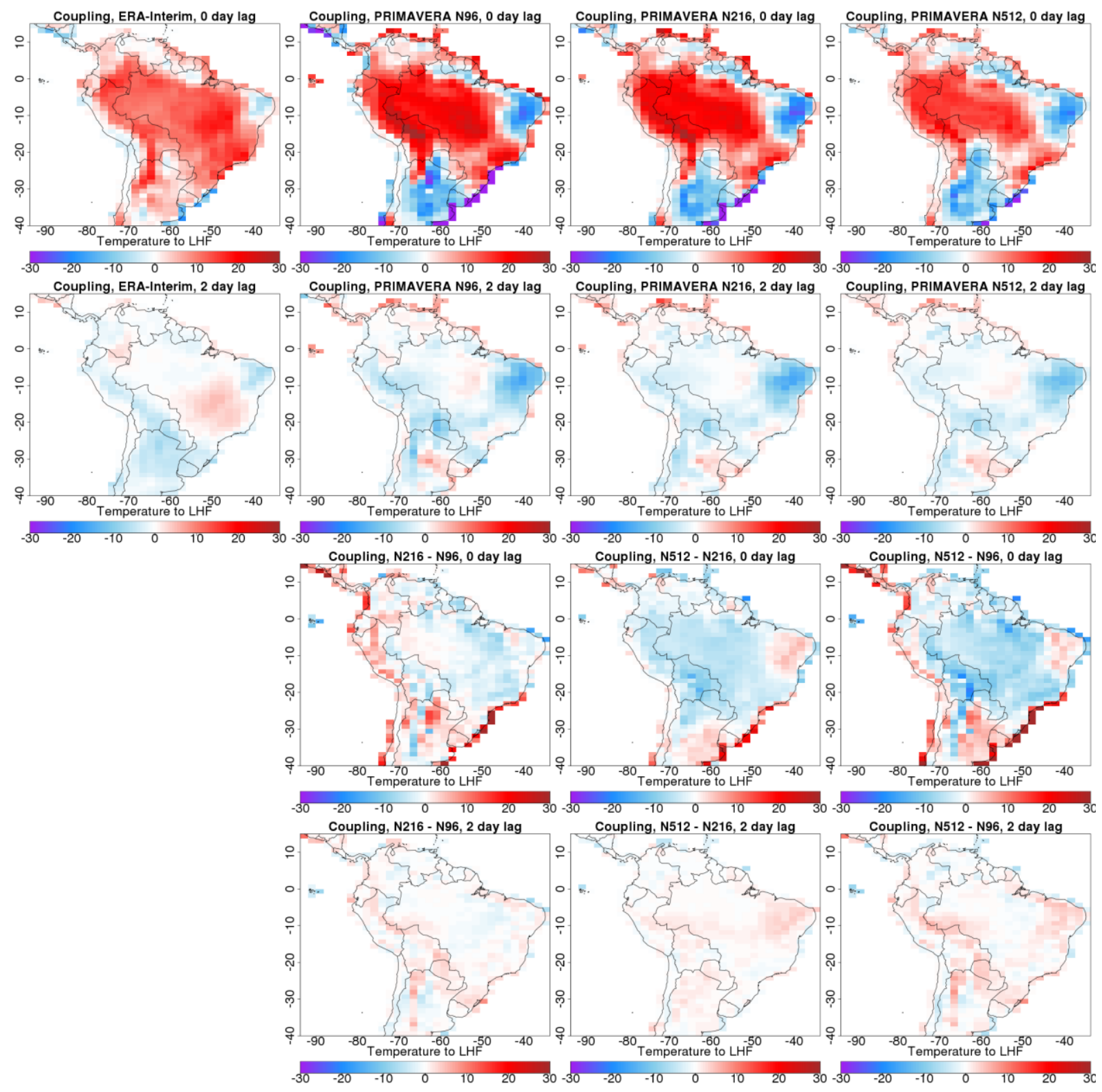

Figure S8: Coupling strength $\left(\mathrm{r}_{\mathrm{a}, \mathrm{b}} \sigma_{\mathrm{b}}\right)$ between daily temperature and latent heat flux during the southern summer wet season (DJF). Daily data from PRIMAVERA model ensembles (1950-2014) at 3 resolutions, and ERA-Interim reanalysis (1979-2014). Showing the results from ERA-Interim, differences between PRIMAVERA and ERA-Interim results, and differences between PRIMAVERA results at different resolutions, for 0 time lags and 2 day time lags (the soil situation 2 days after precipitation). 

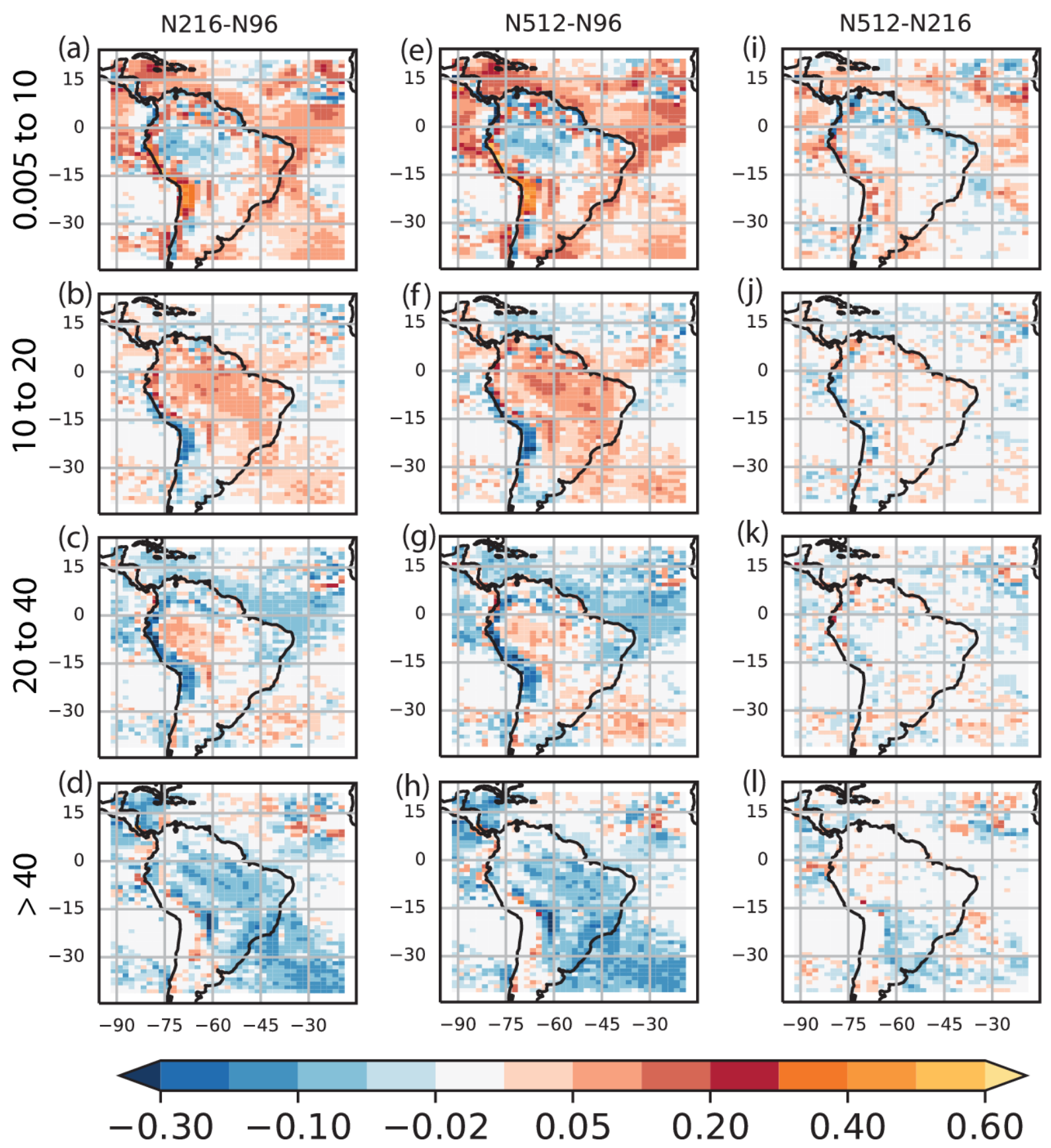

Figure S9: Differences in the fractional contribution to the total precipitation rate from ranges of intensity bins shown in the labels above each pane between N216 and N96 (a-d). The four ranges of intensity bins are (a) 0.005 to $10 \mathrm{~mm} /$ day, (b) 10 to $20 \mathrm{~mm} /$ day, (c) 20 to $40 \mathrm{~mm} /$ day and (d) >40 $\mathrm{mm} /$ day. Same as for N96-CMORPH but for N512 and N96 (e-h) and N512 and N216 (i-l). 


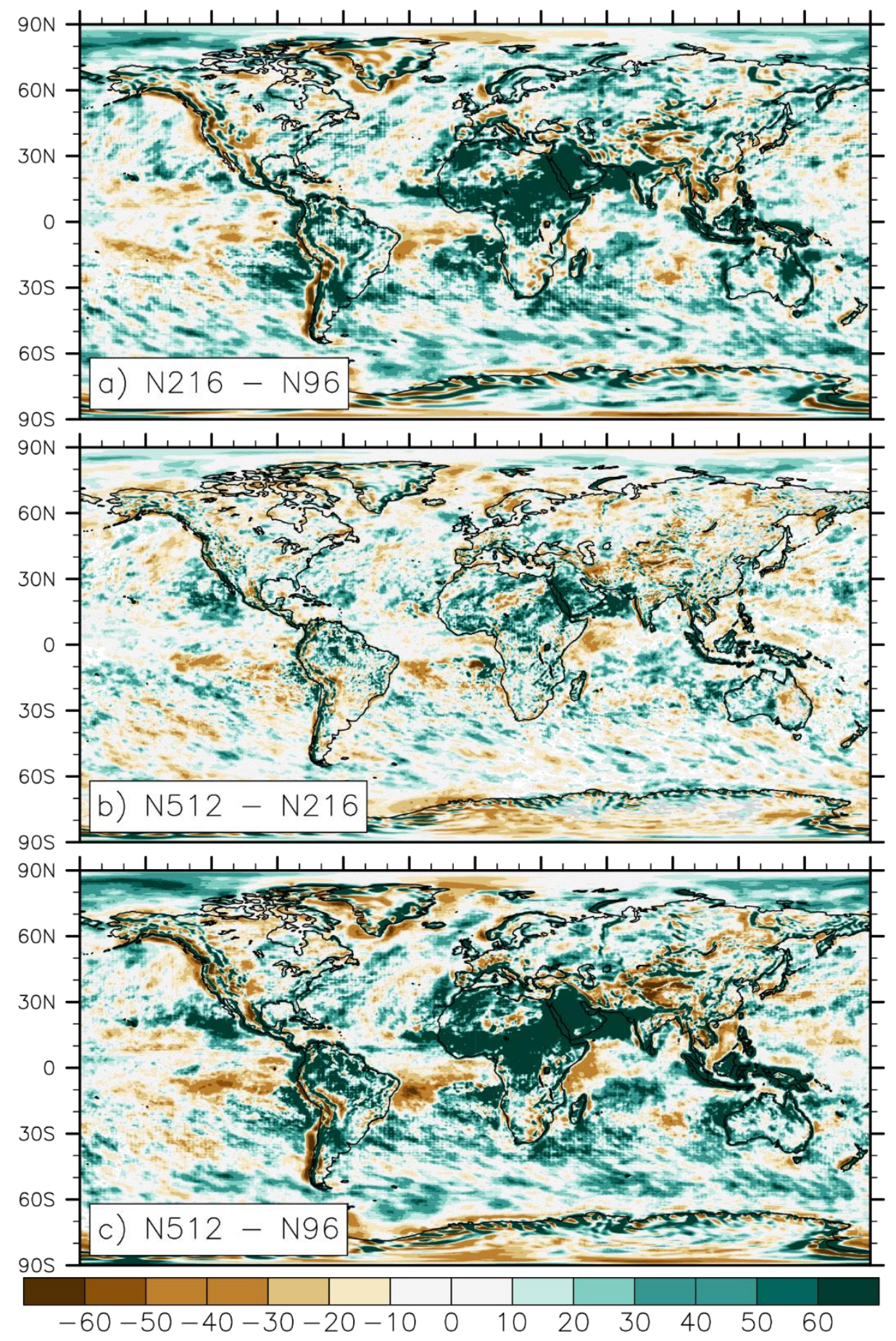

Figure S10: Ensemble-mean difference in annual mean precipitation variance (in \%) for (a) N216-N96, (b) N512-N216 and (c) N512-N96. 